\title{
POR QUE É MAIS FÁCIL CRIAR EMPRESAS QUE COOPERATIVAS? Uma análise das lógicas econômicas capitalista e solidária.
}

\section{Leticia Cristina Bizarro Barbosa ${ }^{1}$}

\section{INTRODUÇÃO}

O objetivo da construção deste artigo é a reunião de ideias sobre as formas de se pensar o desenvolvimento econômico e sustentável dentro do Grupo Interdisciplinar de Administração, Relações Internacionais e Turismo (GIPART) da Unisul ${ }^{2}$, a partir das discussões sobre a constituição de cooperativa de produção de uma Usina de Biodiesel e as dificuldades de se constituir esta personalidade jurídica.

O trabalho aborda a discussão sobre temas como o sistema econômico capitalista, a crítica ao mecanismo de integração econômica capitalista, os distintos princípios de integração econômica, outras lógicas econômicas e um "espírito" cooperativista. A linha de pensamento apresentada aqui indica argumentos sobre um sistema econômico em colapso e a necessidade de assumir uma nova postura quanto à lógica a ser seguida na construção ou transformação de paradigmas. A lógica de trabalho de uma cooperativa entra em conflito com a lógica capitalista de busca incessante do lucro e, somente deste, acaba inviabilizando tais empreendimentos.

Sabe-se que um sistema econômico nos moldes capitalista possui uma racionalidade que orienta a maximizar cada vez mais o lucro. O sistema financeiro, praticamente, tem vida própria, ou seja, não se movimenta em função do sistema produtivo com objetivo de sanar as necessidades de forma ampliada de todos que dele participam. Estas constatações sobre o capitalismo se mostram no modelo de desenvolvimento econômico que se adota: tomando em

\footnotetext{
${ }^{1}$ Professora universitária e coordenadora de curso de graduação em Gestão de Cooperativas na Unisul. Doutoranda em Sociologia Política na UFSC. Contato: leticia.barbosa@unisul.br

${ }^{2}$ Universidade do Sul de Santa Catarina
} 
conta todos os princípios e doutrinas que regem o sistema econômico capitalista como a incessante acumulação de capital.

Inicialmente, serão abordadas importantes temáticas relacionadas ao modo capitalista de produção. É preciso compreender, em aspectos gerais, o modelo econômico diante de qual desenvolvimento sustentável se apresenta como alternativo.

\section{O SISTEMA ECONÔMICO CAPITALISTA}

Estamos diante de uma era em que o sistema econômico hegemônico é o capitalista. Toda a reprodução da vida tende a passar pelo mercado, desde a comida que nos alimenta até o nosso lazer. Ainda que existam outras formas de integração econômica contemporâneas ao capitalista, como formas socialistas, cooperativas e indígenas, o sistema capitalista continua caracteristicamente hegemônico.

A teoria neoclássica compreende os mercados como organizadores do processo de troca. Assim, a partir de uma definição formalista, esta linha teórica entende a economia como a ciência da alocação de recursos escassos entre as múltiplas necessidades, e considera a riqueza social como "todas as coisas tangíveis e intangíveis que são escassas, ou seja, por um lado úteis e, por outro, existem à nossa disposição, em quantidades limitadas" (WARLAS, 1987, p. 155).

Assim, a escassez se torna um requisito necessário levado em consideração para se constituir em riqueza social. Caso contrário, se eles são úteis, mas não escassos, não são considerados membros da riqueza social. Este argumento nos leva a dizer que: se uma coisa é útil e escassa, então é preciosa e intercambiável, e, portanto, torna-se algo que deve ser apropriada.

O mercado aparece como o lugar onde os proprietários destas coisas úteis e escassas contribuem para trocar por outros de natureza similar. Por isso, entre esses elementos da riqueza social, a economia prevê "uma relação sólida que, independentemente da utilidade direta que eles têm, cada um adquire uma propriedade especial, o direito de trocarem um produto pelo outro nas proporções pré-determinadas" (WARLAS, 1987, p. 157).

Em Tese, Florianópolis, v. 11, n. 2, jul./dez., 2014. ISSN: 1806-5023 


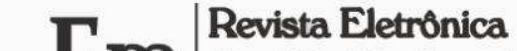

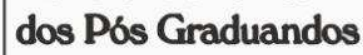

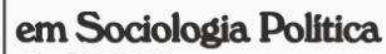 da UFSC}

Desta forma, os produtos não possuem valor antes de chegar ao mercado, o qual thes confere valor de troca, justamente no processo de intercambio. Warlas (1987) acredita que o valor de troca, uma vez determinado, é um fenômeno natural: "natural de origem natural, em sua aparência natural e em sua essência” (WARLAS, 1987, p. 157). A partir do mesmo raciocínio, os preços se tornam algo natural também.

$\mathrm{Na}$ verdade, todo produto tem valor mesmo que não passe pelo mercado. Neste caso, fala-se em valor de uso. Para dar substância às suas teorias, a economia neoclássica parte de pressupostos significativos sobre o comportamento dos agentes e do funcionamento dos mercados. Por um lado, considera-se que os indivíduos (homines economici) são sujeitos racionais que fazem as melhores decisões possíveis com base em informações disponíveis. Neste contexto, considera-se que os indivíduos, isoladamente, são egoístas, utilitários, não são objeto de ligação com os outros e só se preocupam com eles mesmos.

Por outro lado, acredita-se que os mercados são eficientes alocadores de recursos. Por sua vez, a teoria neoclássica postula que os mercados são perfeitos: a existência de inúmeros compradores e vendedores determina que os preços sejam fixados pela oferta e demanda, mas nenhum deles conseguiu impor condições. Como corolário, esta teoria defende que, se estes indivíduos forem deixados a operar livremente, a economia vai chegar ao ideal. Este ideal, conforme o Princípio de Pareto, entende-se esta como uma situação em que é possível melhorar o bem-estar de uma pessoa sem prejudicar outras pessoas.

Voltando para a sociedade capitalista atual em que vivemos, verificamos que muitos dos pressupostos desta teoria não são cumpridos. Os mercados têm um papel fundamental na formação da nossa vida. A fim de alcançar o nosso sustento, ou seja, ter os bens necessários que precisamos para viver, é necessário primeiro contribuir com o caráter de vendedores no mercado. É no mercado que nós obtemos nossas receitas, e é para ele que voltamos, a fim de comprar os produtos que atendem às nossas necessidades. Neste sentido, vemos que grande parte da nossa vida é mercantilizada e, assim, nossa renda é derivada da venda de qualquer produto, não importa o quê. É por isso que, não tendo os meios de produção necessários para produzir, o que nos resta é a vender a própria força de trabalho.

Mas sabe-se como a força de trabalho se torna uma mercadoria? No modo capitalista de produção, os trabalhadores encontram-se duplamente livres, isto é, livres de todos os laços de dependência pessoal e de qualquer posse. Assim, numa economia onde é necessário obter

Em Tese, Florianópolis, v. 11, n. 2, jul./dez., 2014. ISSN: 1806-5023 
os lucros da venda para assegurar os bens necessários para reproduzir suas vidas, e não tendo outros bens, estes indivíduos não têm outra alternativa senão vender o seu trabalho e por esta razão tornam-se uma commodity (mercadoria).

Conforme argumenta Polanyi (1997), embora o trabalho não tenha sido produzido para venda, torna-se uma mercadoria fictícia e é vendido em mercados como qualquer outra mercadoria. Portanto, a vida é estruturada de acordo com o mercado, o que significa que a produção das mercadorias não visa atender às necessidades das pessoas, mas tornou-se um meio para o lucro e a acumulação sem limites.

Em suma, os capitalistas estão em função da organização do processo de produção e esperam, através da venda de bens produzidos, recuperar seu capital. Isto é, para obter uma soma maior do que a investida inicialmente. Neste contexto, a criação de valores de troca é o que orienta a produção, independentemente do uso que eles fazem.

Este sistema de produção, para o seu funcionamento, não exige todo o pessoal que está disponível para venda. Há uma massa marginal da população (NUN, 1999) que o sistema não requer para sua operação e, portanto, não garante sua reprodução. Desta forma, o mercado tem uma racionalidade instrumental (meio-fim), que não leva em conta a necessidade de reproduzir a vida de todos os povos. Deste modo, Franz Hinkelammert (2003a, 2003b, 2009) nos explica que as operações destes mercados capitalistas não têm uma racionalidade reprodutiva. Tal autor, assim como outros, propõe uma crítica à operação lógica desses mercados.

\section{A CRÍTICA AO MECANISMO DE INTEGRAÇÃO ECONÔMICA CAPITALISTA}

Hinkelammert (HINKELAMMERT, 2003a; HIKELAMMERT e JIMÉNEZ, 2003b; HIKELAMMERT e JIMÉNEZ, 2009) tem sido um dos principais autores que critica a racionalidade econômica, entendida como relação meio-fim instrumental, característica da sociedade capitalista. Os pressupostos subjacentes a esta lógica consideram que os indivíduos são homines economici racionais, que tomam as melhores decisões possíveis com a

Em Tese, Florianópolis, v. 11, n. 2, jul./dez., 2014. ISSN: 1806-5023 
informação disponível e, além disso, são hedonistas. Assim, considera-se que qualquer ato econômico implica uma escolha determinada pela escassez; enquanto os indivíduos forem racionais, esta será a lógica.

Nesta visão neoclássica, portanto, entende-se que o indivíduo deve ser orientado pelo seu interesse hedonista, que lidera o mercado por meio da interação com outros indivíduos semelhantes, com uma atribuição mais eficiente dos recursos. Nesse sentido, Adam Smith (1996) proferiu que o mercado, com sua mão invisível, permite aos indivíduos, seguindo seus próprios interesses, contribuam para o interesse geral. Assim, esta visão afirma que há uma ordem de mercado, decorrentes da ação fragmentada de indivíduos. Este princípio da "mão invisível" rege que: num mercado livre em que cada agente econômico atua com vista apenas à persecução dos seus próprios objetivos, se atinge uma situação econômica que beneficia todos. O mecanismo de mercado funciona assim como uma "mão invisível" que conduz os agentes econômicos para uma situação ótima do ponto de vista da eficiência.

Esta ordem é vista por Adam Smith e pelos economistas clássicos que o seguiram como efeito indireto da ação direta. Pensa-se que o mercado se autorregula e contribui para o interesse geral. Agora, se analisar a realidade, verá que não existe este mercado autorregulado. Ao contrário, o mercado gera exclusão e a pobreza. Precisamente em relação a isto, Hinkelammert (HINKELAMMERT, 2003a; HIKELAMMERT e JIMÉNEZ, 2003b; HIKELAMMERT e JIMÉNEZ, 2009) afirma que o mercado traduz a ética de mercado em uma ética da irresponsabilidade.

Esta crítica se deve ao fato de que os mercados são movidos pela racionalidade, que é destrutiva das duas fontes de riqueza: o ser humano e a natureza (HINKELAMMERT, 2003a). Esta negligência à vida humana e à natureza faz com que o mercado seja orientado por uma ética da irresponsabilidade.

Os seres humanos não são considerados responsáveis pelos efeitos indiretos das nossas ações, e foi atribuída ao mercado a responsabilidade de agir no interesse geral. No entanto, o mercado não seria um reflexo de nossas ações? A partir deste ponto de vista, ao contrário do neoclássico, é preciso compreender os efeitos indiretos que levam à ação direta. Muitas vezes, estes efeitos não são intencionais, mas eles existem e devem ser levados em conta tanto quanto a ética do mercado, que é destrutiva, devorando o homem e a natureza. 
Nesse sentido, para Hinkelammert (2003a, p. 32), "a racionalidade meio-fim é a irracionalidade do racionalizado, uma vez que é a ineficiência da eficiência". Perder o sentido da vida humana é irracional, pois elimina o próprio objeto da ação, ou seja, elimina o fim.

Portanto, torna-se necessário substituir o mercado da ética da irresponsabilidade, para garantir a vida de todos. Trata-se de uma ética do bem comum, onde os efeitos indiretos sobre a vida são considerados dentro das escolhas individuais de todos. A partir desta perspectiva, o sujeito racional é aquele que está consciente da importância de cuidar da natureza e leva em conta que a ação fragmentada pode resultar em suicídio (na destruição de outros): "como o sujeito precede seus propósitos, o circuito natural da vida humana precede o sujeito" (HINKELAMMERT, 2003a, p. 46).

$\mathrm{Na}$ racionalidade reprodutiva, a "outra" racionalidade, delibera-se sobre a racionalidade de meios-fins, e considera-se que estes devem ser compatíveis com a reprodução da vida dos indivíduos. O verdadeiro critério de racionalidade é o da vida ou morte. Os meios e fins da racionalidade, em todos os casos, são incompatíveis com esta abordagem, porque "a racionalidade de meios e fins esmaga a vida humana (e natureza), que mostra seu caráter potencialmente irracional” (HINKELAMMERT, 2003a, p. 49).

Sem dúvida, a premissa subjacente é que, com as novas tecnologias e a riqueza acumulada no processo de produção capitalista, é possível gerar bastantes produtos, capazes de satisfazer as necessidades de todos. No entanto, sob o sistema de mercado que regula a sociedade, uma parte significativa da população não chega a ter acesso a esta riqueza, pois ela não tem poder aquisitivo suficiente. Nesse sentido, conforme Lisboa (2004b), acredita-se que o capitalismo se apresenta como um sistema que produz de forma eficiente, mas apresenta problemas na distribuição de resultados. Assim, se a lógica proposta é o da reprodução ampliada da vida (HINKELAMMERT, 2003a; HIKELAMMERT e JIMÉNEZ, 2003b; HIKELAMMERT e JIMÉNEZ, 2009), não do capital, a riqueza social deve ser distribuída entre todos os membros da sociedade, de forma igual, e não concentrada nas mãos dos donos do capital.

\section{4. “ESPÍRITO” COOPERATIVISTA}




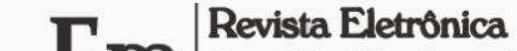

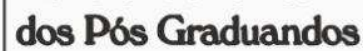

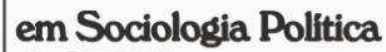 da UFSC
}

O "espírito" cooperativista é um conjunto de sentimentos de amor ao próximo, um comprometimento coletivo e solidário, onde a responsabilidade está intimamente ligada a este comprometimento com o grupo e à necessidade de união para prosperar. Cattani relaciona a utopia da seguinte forma:

\begin{abstract}
A liberdade criadora que busca a emancipação social se manifesta na luta contra os dogmatismos, messianismos e determinismos estruturais, contra a servidão e violência, enfim, contra o domínio das minorias reacionárias o tutelares (CATTANI, 2004, p. 15).
\end{abstract}

Historicamente, este "espírito" já se encontrava presente em antigas civilizações, como os Incas, Mapuches e Guaranis. Sobre as Reduções criadas pelas Missões Jesuítas, vale lembrar que os povos Guaranis possuíam um "espírito" ainda mais cooperativo que os jesuítas com suas propostas. $\mathrm{O}$ trabalho coletivo era uma instituição e não se pensava no trabalho limitado somente a família como era a proposta dos Jesuítas que vieram da Europa.

Com a Revolução Industrial, iniciada na Inglaterra no Século XVIII, uma concepção cooperativista ressurge com os ideais utópicos de Robert Owen $(1771$ - 1858) e Charles Fourier (1772-1837).

O "espírito" cooperativista não segue os mesmos preceitos do "Espírito" do Capitalismo descrito por Marx Weber (1985). Weber (2004) atribui este espírito do capitalismo a um "novo estilo" em que jovens empresários passam a constituir fábricas com trabalhadores e investir o capital nelas em vez de ser destinado ao rendimento a juros.

O empresário capitalista tem "suficiente imparcialidade, extraordinária firmeza de caráter, sóbrio domínio de si, clarividência e capacidade de ação estão entre as qualidades "éticas" ao implementar tais inovações" (WEBER, 2004, p. 61).

Weber complementa explicando que isso "lhes possibilitam angariar a confiança desde logo indispensável dos clientes e dos operários e lhe dão energia para superar incontáveis resistências, mas, acima de tudo, para assumir o trabalho infinitamente mais intenso que agora é exigido do empresário (...)" (WEBER, 2004, p. 61). Weber falava de "homens criados na dura escola da vida, a um só tempo audazes e ponderados, mais sobretudo sóbrios $e$ constantes, sagazes e inteiramente devotados à causa, homens com visões e 'princípios' rigorosamente burgueses" (WEBER, 2004, p. 61).

Em Tese, Florianópolis, v. 11, n. 2, jul./dez., 2014. ISSN: 1806-5023 
Quando Weber diz que "a aquisição econômica não mais está subordinada ao homem como um meio para a satisfação de suas necessidades materiais" (WEBER, 1985, p. 21), ele quer dizer que o homem está submetido a exploração do capital e suas necessidades de reprodução de suas vidas não valem tanto quanto a valorização do dinheiro. Considerando que o contrário seria irracional.

Outra questão defendida seria o trabalho. E é neste ponto que entra a geração de lucro. Fundamentado neste espírito do capitalismo, o lucro significa trabalho não pago pelo capitalista de acordo com Marx em sua obra O Capital (MARX, 1995). Isto é, o empresário tem lucro porque ele não paga tudo que o trabalhador produz. Esta teoria desenvolvida por Marx vem ao encontro do que Weber defende: "um excesso de mão de obra que possa ser empregada a baixo preço no mercado de trabalho é uma necessidade para o desenvolvimento do capitalismo" (WEBER, 1985, p. 24).

Bom, sabe-se que lucro é uma coisa, sobra é outra. Cooperativa não tem lucro, tem sobra. Sobra possui um significado diferente, em que se realiza uma remuneração proporcional ao trabalho realizado. Com isso, não sobra lucro no final das contas.

Voltando ao espírito de cooperação, Donida explica que possuir espírito cooperativista não deve significar um sentimento de renúncia:

\begin{abstract}
É fundamental saber harmonizar conflitos desta ordem e ter claro até onde se chega, ou se deve chegar, o espírito de cooperação e de solidariedade, e quando este deixa de ser um referencial a sustentar. Benecker (1980) ensina que a solidariedade cooperativa deve ser racional. Com isso, entende-se que as vantagens da união associativa devem sobressair os efeitos negativos das divergências entre interesses e objetivos pessoais e os que prevaleçam para o conjunto dos associados. O resultado global de pertencer à associação deve ser vantajoso para cada associado e não uma permanente necessidade de renúncia (DONIDA, 2004, p. 97) . $^{3}$.
\end{abstract}

Há uma diferenciação entre espírito cooperativista, explicado acima, e os princípios cooperativistas. Em sua definição, os princípios cooperativistas são linhas orientadoras que as cooperativas seguem de forma a levar os seus valores à prática. Os princípios do cooperativismo são sete: $1^{\circ}$ - Adesão voluntária e livre; $2^{\circ}$ - Gestão democrática; $3^{\circ}$ -

\footnotetext{
${ }^{3}$ Tradução feita pela autora.
}

Em Tese, Florianópolis, v. 11, n. 2, jul./dez., 2014. ISSN: 1806-5023 
Participação econômica dos membros; $4^{\circ}$ - Autonomia e independência; $5^{\circ}$ - Educação, formação e informação; $6^{\circ}$ - Intercooperação; $7^{\circ}$ - Interesse pela comunidade.

Afinal, como pode-se colocar em prática uma lógica econômica cooperativista e solidária que desenvolva políticas públicas prioritárias? Ao explicar a sustentabilidade, não só do empreendimento em si, mas do sistema é possível identificar caminhos possíveis.

\section{SUSTENTABILIDADE ECONÔMICA - ANÁLISE MACRO E MESOECONÔMICA}

Diante disso, repensar o econômico nos remete a refletir sobre o sustentável.

Deve ser considerado nesta discussão o fato de se ter tomado por muitos anos a industrialização como único motor de desenvolvimento na economia através da promoção das grandes empresas e grupos econômicos. Um motor poderoso que aos poucos perdeu seu propósito de desenvolvimento econômico e ainda vem perdendo por gerar cada vez mais desemprego com a substituição de postos de trabalho pela tecnologia (computadores e robôs automatizados). Isso passou a abrir espaço para políticas de desenvolvimento rural, por exemplo, para se evitar o êxodo rural, e o entendimento que a economia produtiva se movimenta no âmbito das micro e pequenas empresas.

As consequências decorrentes dos modelos de desenvolvimento implementados trouxeram a necessidade de se atentar para novos modelos de desenvolvimento econômicos mais sustentáveis e a um novo estilo, como diz Weber (2004).

Como o tema da sustentabilidade não se limita ao nível microeconômico, considerase, então, um conceito de economia que se identifica com a economia social:

A economia, em sua expressão mais profunda e abrangente, é o sistema de instituições e práticas que se dão em uma comunidade ou em uma sociedade de comunidades e indivíduos para definir, mobilizar, ou gerar, distribuir e organizar combinações de recursos (relativamente escassos ou não), com a finalidade de produzir, intercambiar e utilizar bens e serviços úteis para satisfazer, da melhor 
forma possível e através das gerações, as necessidades que se estabelecem como legítimas para todos os seus membros (CORAGGIO, 2007d, p. 71) ${ }^{4}$.

Pensar o econômico muito além da satisfação imediata das necessidades ilimitadas com os recursos escassos e justamente levar em consideração as gerações futuras e as necessidades legítimas para construir uma economia social, justa e sustentável.

A sustentabilidade consiste em um sistema institucionalizado de organização e reprodução de um sistema econômico cooperativo (BARBOSA, 2011). O importante é ter em conta que não se trata de assistencialismo promovendo políticas de subsídios às cooperativas. Há aspectos relevantes a serem considerados para analisar a sustentabilidade dos empreendimentos de economia social que não passam pelos critérios capitalistas. Com isso, a sustentabilidade passa por uma mudança de perspectiva de visão econômica, incluindo o conceito de economia.

Para ser sustentável de acordo com o "critério mercantil estrito", o empreendimento solidário ou cooperativo deveria ser capaz de se autossubsidiar e não esperar subsídios do Estado, isenções fiscais ou crédito especial, nem poderiam se favorecer da exploração dos recursos naturais. Além disso, deveriam ter um excedente econômico monetário para estabelecer sua eficiência (CORAGGIO, 2007d, p. 92). Isso não costuma ocorrer nem nos empreendimentos capitalistas, porque eles não conseguem cumprir esse critério.

A sustentabilidade, que é defendida em uma economia solidária, envolve não apenas os resultados monetários, mas também construir relações sociais distintas das construídas pela racionalidade hegemônica, que considera tudo redutível a um valor mercantil. Dentro dessa abordagem, a sustentabilidade inclui questões como: conservação da natureza, preços justos, qualidade das relações de trabalho (CORAGGIO, 2007c, p. 92).

Segundo Coraggio (2007d), a relação dos empreendimentos de economia social e solidária e o Estado deve ser estreita e as políticas socioeconômicas devem ser construídas e concebidas de forma participativa com os atores coletivos. A institucionalização de uma lógica coletiva e solidária de produção em um complexo público de administração do Estado,

\footnotetext{
${ }^{4}$ Tradução feita pela autora.

5 Quando falamos em "sustentabilidade econômica mercantil estrita", nos referimos à concepção de sustentabilidade que passa pela eficiência empresarial "sem subsídio externo de nenhum tipo (nem financeiro, nem explorando a natureza)" (CORAGGIO, 2007d, p. 91).
} 
fortalece a sustentabilidade desses empreendimentos por meio da implementação de políticas socioeconômicas e da estrutura dos departamentos de Estado e de setores que trabalhem simultaneamente com diferentes racionalidades econômica.

Podemos citar a diferença gritante entre a carga tributária aplicada à micro e pequenas empresas, o SIMPLES, e a carga tributária aplicada às cooperativas. A prioridade para o Estado não são as cooperativas, mas sim o empreendedorismo individual. Encontramos políticas públicas de incentivo a esta configuração empresarial, pois esta se encaixa no modelo econômico e submete-se a lógica econômica hegemônica. Já as cooperativas parecem estar na contramão da eficiência e do progresso econômico e social.

A cooperativa assume papel importante na economia quando é incorporado as estruturas verticais de redes empresariais, mesmo assim não seria a ideal:

El Estado promueve el cooperativismo y otras formas asociativas, pero defiende la verticalización de la producción que puede ser entendida como una articulación cooperativa en formato top-down (BARBOSA, 2007). Es decir, la cadena de valor puede estar a cargo del empresariado mientras los productores se organizan en cooperativas para facilitar la agregación de valor en la punta de la cadena, donde están las industrias (BARBOSA, 2011, p. 80).

Neste contexto, os produtores não consegue competir com empresas capitalistas e tendem a ser expulsos do sistema ou incorporados como empreendedor individual, micropequena empresa ou como trabalhador empregado das empresas (BARBOSA, 2011).

\section{USINA DE BIODIESEL DA PINHEIRA (PALHOÇA/ SANTA CATARINA)}

As políticas públicas devem ser pensadas desde a concepção de economia social e solidária (SINGER, 2007; CORAGGIO, 2007b; HINKELAMERT, 2003a; HINKELAMERT e JIMÉNEZ, 2003b), porque somente assim as cooperativas assumiriam o papel de ator econômico propulsor do desenvolvimento sustentável. 
A Usina de Biodiesel é um exemplo desta incoerência, gerenciada por uma associação, Pro-CREP, uma organização civil dotada de personalidade jurídica de direito privado, sem fins lucrativos. Ela produz Biodiesel a partir do óleo de cozinha usado.

A Associação buscava constituir uma cooperativa para comercializar o biodiesel, produto proveniente da reciclagem do óleo de cozinha. E é neste ponto que as discussões entre os membros do grupo sobre que tipo de pessoa jurídica deve ser criada foram surgindo e levantaram diversas questões cruciais entre a ideologia e sua lógica de produção cooperativa e solidária e a melhor forma de se inserir no mercado levando-se em conta a carga tributária, linhas de crédito, apoio, políticas públicas do Estado e competitividade.

Somente um planejamento estratégico do empreendimento coletivo e solidário pensado e construído conjuntamente com o levantamento de dados inerentes deste tipo de empreendimento, que o difere de uma empresa convencional, no desenvolvimento das ações para a constituição da cooperativa, torna possível este passo. Além disso, a metodologia de trabalho, profissionais que entenderem as particularidades da gestão de cooperativas, contabilidade cooperativa, etc. nos órgãos governamentais, de apoio e de fomento, são necessários para a execução das políticas públicas. Sem levar em conta as características subjetivas do grupo, o diagnóstico seguramente apontará para a não constituição de uma cooperativa, mas sim de uma microempresa.

Diferente da configuração da associação, a cooperativa pode comercializar. A cooperativa está embasada em princípios que definem uma forma diferente de gestão respeitando a solidariedade, a igualdade, democracia e a coletividade. Trata-se de uma racionalidade econômica que a economia social e solidária representa.

Economia solidária é uma forma econômica em que o trabalho é coletivizado e não alienado, a terra e os meios de produção estão nas mãos dos trabalhadores e tem a cooperativa como umas das principais instituições. Esta linha de pensamento engloba outras instituições em seu movimento, como as comunidades indígenas e os quilombos, por exemplo, para demonstrar que a economia é uma ciência complexa.

Paul Singer (2007) descreve os princípios de organização da economia solidária dentro da instituição que este autor entende ser a mais adequada para sua realização: a cooperativa. Segundo este autor, a cooperativa tem: 


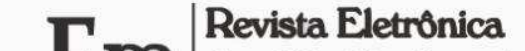

Posse coletiva dos meios de produção pelas pessoas que a utilizam para produzir; gestão democrática por participação direta (quando o número de cooperados não é muito alto) ou por representação; divisão das sobras entre os cooperados por critérios aprovados depois de discussões e negociações entre todos; investimento do excedente anual (sobras) também por critérios acordados entre todos os cooperados (SINGER, 2007, p. 62) ${ }^{6}$.

A autogestão é um fator importante neste processo, pois subentende a existência de autonomia e pressupõe capacitação para a administração coletiva do negócio: autonomia tanto nas unidades produtivas quanto em sua instância representativa, isto é, sem dependência dos órgãos governamentais, universidade ou outras organizações de apoio.

Mesmo possuindo fundamentos e bases diferentes das empresas convencionais, as cooperativas também são consideradas uma organização empresarial e segue as mesmas normas de mercado que as empresas, por isso o planejamento tem que considerar a sua participação no mercado global, mesmo que sua atuação seja local no primeiro momento.

A Pro-CREP segue e defende os princípios de uma economia solidária, assumindo um ethos diferente ao que Weber expõe do jovem empresário inovador. A Associação reúne mais de 30 pessoas que trabalham em diferentes atividades, como a triagem de materiais recicláveis, reutilização de materiais da construção em mosaicos e os produtos derivados do óleo de cozinha: biodiesel, outros derivados do processo e sabão. A proposta de produção do biodiesel é, inicialmente, para atender aos pescadores da associação da Pinheira na demanda por combustível para os barcos. Com o tempo, a Usina passou a atender indústrias de solventes e outros destinos químicos foram sendo dado. A Usina buscou formar uma cooperativa, pois o grupo já possui a sistemática de decisão democrática e solidária entre os membros, além do respeito a natureza e o objetivo de contribuir para a conservação da mesma. Muitas reuniões foram realizadas com profissionais, professores da universidade e bolsistas mostrando os prós e contras de se abrir uma cooperativa e uma pequena empresa, fazendo várias simulações e cálculos, recebendo consultoria do Banco do Brasil, SEBRAE e outros instituições. Mesmo assim, o grupo não conseguiu constituir a cooperativa e a decisão foi tomada com base, primeiramente, no receio de desagregação do grupo depois de uma mudança na pessoa jurídica. Depois foram se somando outros fatores como a carga tributária

\footnotetext{
${ }^{6}$ Tradução feita pela autora.
}

Em Tese, Florianópolis, v. 11, n. 2, jul./dez., 2014. ISSN: 1806-5023 
ser mais pesada para uma cooperativa e a rede de apoio institucional estar mais articulada para atender a uma pequena empresa que uma cooperativa.

\section{CONSIDERAÇÕES FINAIS}

A Usina de Biodiesel é um dos vários exemplos espalhados pelo Brasil que passaram pela dificuldade de colocar em prática, no mercado, suas convicções e princípios, ao querer constituir uma cooperativa. O foco deste trabalho é discutir a lógica que está por detrás das dificuldades de muitos grupos. A partir disso, constata-se a necessidade de se promover mudanças na forma de se pensar a economia e promover o "espírito" cooperativista de forma a compor a lógica econômica que rege a dinâmica do sistema econômico e o desenvolvimento de políticas públicas. É necessário fortificar os fundamentos de uma economia social e repensar a economia de maneira que tenha o cooperativismo como prioridade.

Frente ao sistema econômico capitalista, o Estado deveria contribuir mais com políticas públicas de fomento, políticas tributárias e investimentos para o desenvolvimento de economias cooperativas, de maneira a promover o cooperativismo e sua sustentabilidade.

Muitas das relações entre os âmbitos macroeconômico e o microeconômico passam pelo mesoeconômica, inclusive a sustentabilidade. As instituições de pesquisa e de extensão como as universidades, além de outras organizações como SEBRAE deveriam estruturar-se melhor para atender as cooperativas como ator econômico eficiente social, econômico e ambientalmente sustentável, formando uma rede mesoeconômica de articulação de fomento.

\section{REFERÊNCIAS}

BARBOSA, Letícia Cristina Bizarro. Los actores de la economía solidaria, sus desafíos y límites en el sistema capitalista de mercados. Los maricultores de São Francisco do Sul Santa Catarina/Brasil. Buenos Aires: UNGS, 2011. 
, Letícia Cristina Bizarro. Cooperativas articuladas em rede e o mercado: o sucesso das estratégias da Cooperação Cooperativa Mondragón. Revista Espaço Acadêmico, n 70 , ano VI, 2007.

COMAS D’ARGEMIR, Dolors Antropología Económica, Barcelona: Editora Ariel, 1998.

CORAGGIO, José Luis La economía social y la búsqueda de un programa socialista para el siglo XXI, Revista Foro, Los socialismos del Siglo XXI, Opciones en debate, Nº 62, Bogotá, octubre/ 2007a, páginas 43-44.

, José Luis. Economía social, acción pública y política (Hay vida después del neoliberalismo). Buenos Aires: CICCUS, 2007b.

, José Luis La economía social y la búsqueda de un programa socialista para el siglo XXI, Revista Foro, Los socialismos del Siglo XXI, Opciones en debate. no 62, Bogotá, 2007c.

, José Luis. La economía social desde la periferia. Buenos Aires: Altamira, 2007d.

DANANI, Claudia. El alfiler en la silla: sentidos, proyectos y alternativas en el debate de las políticas sociales y de la Economía Social. In: DANANI, C. (org.). Política Social y Economía Social: debates fundamentales. Buenos Aires: UNGS/OSDE/Editorial Altamira, 2004.

DONIDA, Domingos Armanda. Cooperación internacional. In: CATTANI, Antonio David (org.). La otra economía. Buenos Aires: UNGS/Editorial Altamira/Fundación OSDE, 2004.

GOMES, Carlos. Antecedentes do capitalismo. Portugal: Almada, 2008.

HINKELAMMERT, Franz. El sujeto y la ley. El retorno del sujeto reprimido. EUNA: Heredia, 2003.

Em Tese, Florianópolis, v. 11, n. 2, jul./dez., 2014. ISSN: 1806-5023 
HIKELAMMERT, Franz J. \& Henry Mora Jiménez 2003 Por una economía orientada hacia la vida, Economía y Sociedad, Editorial Departamento Ecuménico de Investigaciones, San José.

HIKELAMMERT, Franz e JIMÉNEZ, Henry Mora Economía, sociedad y vida humana: Preludio a una segunda crítica de la economía política. Buenos Aires: Altamira, 2009.

HOBSBAWM, E. "Introducción" a Marx, K. en Marx, K. Formaciones económicas precapitalistas, Córdoba: Cuadernos de Pasado y Presente Nº 20. 1971.

IPEA. Objetivos de Desenvolvimento do Milênio - Relatório nacional de acompanhamento. Brasília : Ipea, 2004.

KATZ, Hagai. Gramsci, hegemonia, e as redes da sociedade civil global. REDES- Revista hispana para el análisis de redes sociales. Vol.12, Junho 2007. Disponível em: < http://revista-

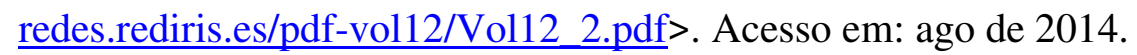

LISBOA, Armando de Melo, Economia Solidária: Similia, similibus curentur (2008) Disponível em: <http://www.ifil.org/rcs/biblioteca/lisboa1.htm>. Acesso em: 12 de fev. 2010.

Armando de Melo, Socioeconomia solidária. Marco conceitual latino-americano (2004a). Disponível em: <http://www.socioeco.org/bdf_fiche-document-758_pt.html>. Acesso em: 12 de fev. 2010.

Armando de Melo. Mercados Solidários. in CATTANI, Antonio David, La Otra Economia. Buenos Aires: Altamira, 2004b.

Armando de Melo. Economía Solidaria: una reflexión a la luz de la ética cristiana. in CORAGGIO, José Luis, La Economía Social desde la periferia. Buenos Aires: Altamira, 2007. 
MARX, Karl. O Capital - Volume I - Livro Primeiro - O Processo de Produção do Capital Tomo 1 e 2. São Paulo: Editora Nova Cultural Ltda., 1995.

NUN, José. El futuro del empleo y la tesis de la masa marginal. Buenos Aires: Revista Desarrollo Económico No 52, Volúmen No 38, IDES, enero-marzo 1999, Pág. 985-1004.

POLANYI, Karl. La economía como proceso institucionalizado, traducción libre de Mirta Vuotto del capítulo "The economy as an instituted process", en Trade and Market in the Early Empires. Economies in History Theory, New York, 1957.

, Karl. El sustento del Hombre. Barcelona: Biblioteca Mondadori, 1994.

, Karl. La gran transformación. Crítica del liberalismo econômico. Madrid: Editorial La Piqueta, presentación y traducción Julia Varela y Fernando Álvarez- Uría, 1997.

SANTOS, Boaventura de Souza (Org.). Produzir para viver: os caminhos da produção não capitalista. Rio de Janeiro: Série Reinventando a Emancipação Social: para novos manifestos, 2002.

SMITH, Adam. Riqueza das Nações/ Investigação sobre sua natureza e suas causas. Volume I. São Paulo: Editora Nova Cultural Ltda., 1996.

WALRAS, León. Elementos de economía política pura (o Teoría de la riqueza social). Madrid: Alianza Editorial, 1987.

WEBER, Max. A Ética Protestante e o Espírito do Capitalismo. 4 ed. São Paulo: Livraria Pioneira Editora, 1985.

WEBER, Marx. A Ética Protestante e o "Espírito" do Capitalismo. São Paulo: Cia. Das Letras, 2004. 


\title{
POR QUE É MAIS FÁCIL CRIAR EMPRESAS QUE COOPERATIVAS? Uma análise das lógicas econômicas capitalista e solidária.
}

\begin{abstract}
Resumo: O presente artigo propõe uma reflexão e discussão acerca da lógica econômica e analisar as dificuldades de desenvolvimento de cooperativas devido aos conflitos de racionalidades econômicas. Através de uma pesquisa bibliográfica e análise de autores que discutem o tema e a observação participativa do processo de constituição de pessoa jurídica da Pro-CREP, reflete-se sobre as seguintes indagações: a economia está pensada para um tipo de empreendimento individual ou associativo, mas que beneficie o individual. Por outro lado, economia social é formada por empreendimentos associativos que busca o benefício coletivo. O sistema não se estrutura para atender este tipo de empreendimento e as leis, os incentivos, políticas públicas, etc. estão pensadas para o desenvolvimento dos empreendimentos individuais. A sustentabilidade da cooperativa passar por outros elementos além da eficiência econômica. E a Usina de Biodiesel da Pro-CREP aparece como exemplo da discussão entre constituir uma cooperativa ou uma pequena empresa.
\end{abstract}

Palavras chaves: Cooperativas. Lógica econômica. Sustentabilidade.

\section{WHY IS EASIER TO CREATE COMPANIES COOPERATIVE? An analysis of capitalist economic logic and solidarity.}

\begin{abstract}
This article proposes a reflection and discussion about the economic logic and analyze the cooperative development difficulties due to conflicts of economic rationality. Through a bibliographic review and analysis of authors who discuss this topic and through aparticipant observation of the corporate formation process of the Pro-CREP, is reflected on the following questions: The economy is thought to a type of individual or associative enterprise, but that benefits the individual. On the other hand, social economy is made up of associative enterprises seeking the collective benefit. The system is not structured to meet this type of enterprise and the laws, incentives, public policy, etc. are designed for the development of individual enterprises. The sustainability of the cooperative pass by factors other than economic efficiency. And the Plant Pro-CREP of Biodiesel appears as an example of discussion between form a cooperative or a small business.
\end{abstract}

Keywords: Cooperatives. Economic logic. Sustainability.

Recebido em: 08 de julho de 2014

Aceito para publicação em: 20 de julho de 2014

Em Tese, Florianópolis, v. 11, n. 2, jul./dez., 2014. ISSN: 1806-5023 